\title{
ABERRANT SITES OF METASTASIS: TWO CASES DIAGNOSED ON FNAC.
}

\author{
Ruchi Srivastava ${ }^{1}$, Preeti Tuli ${ }^{1}$, and Poonam Das ${ }^{2}$ \\ ${ }^{1}$ Max Balaji Hospital Patparganj \\ ${ }^{2}$ Affiliation not available
}

December 19, 2020

\begin{abstract}
Some of the commonly prevalent malignancies may rarely metastasize to aberrant locations in the body. Such cases have not been described adequately in the literature. Two cases presented here show unusual sites of spread, not congruent with present knowledge of metastasis.
\end{abstract}

TYPE OF MANUSCRIPT: Clinical Case Reports

TITLE OF THE ARTICLE: ABERRANT SITES OF METASTASIS: TWO CASES DIAGNOSED ON FNAC

\section{AUTHORS' DETAILS:}

1. Srivastava Ruchi, M.D. Pathology, Consultant, Department of Pathology, Max Lab, Max Super speciality Hospital, Patparganj

2. Tuli Preeti, M.D. Pathology, Senior Consultant, Department of Pathology, Max Lab, Max Super speciality Hospital, Patparganj

3. Das Poonam, M.D. Pathology, Senior Director, Max Lab, Saket, New Delhi

\section{Dr Ruchi Srivastava (Corresponding author)}

Consultant, Pathology,

POSTAL ADDRESS: Department of Pathology, Max Super speciality Hospital, 108 A, IP Extension, Patparganj, NEW DELHI. 110093

TELEPHONE:

+91-11-4303 $3333+91-98-11611549$

EMAIL OF CORRESPONDING AUTHOR: RUCHISRIVASTAVA2007@GMAIL.COM

TITLE OF THE ARTICLE: ABERRANT SITES OF METASTASIS: TWO CASES DIAGNOSED ON FNAC

RUNNING TITLE: ABERRANT SITES OF METASTASIS

KEY WORDS: Aberrant, FNAC, Metastasis

KEY CLINICAL MESSAGE:

As a cytopathologist, we must exercise clinical acumen with detailed clinical history before rushing to any diagnosis. This can benefit both the patient and the clinician to plan the treatment. 


\section{INTRODUCTION:}

Adenocarcinoma of oesophagus and Squamous cell carcinoma of cervix are common malignancies presenting typically and having predictable routes of metastasis ${ }^{1,2}, 3$. Following cases show unusual sites of spread, not congruent with present knowledge of metastasis.

CASE 1: A sixty seven year old male presented to the hospital with a mass in left upper arm for one month. Since the patient was a known case of adenocarcinoma oesophagus (diagnosed two years back), he was advised ultrasonography, CT scan and PET. PET scan revealed FDG avid intramuscular deposits in left triceps brachii, right supraspinatous, posterior abdominal wall muscles and left medial thigh muscles (Fig. I). USG guided fine needle aspiration was done from PET positive mass in left triceps muscle to rule out soft tissue malignancy developing post chemo and radiotherapy. The aspirate smears were cellular and were reported as positive for malignant cells, poorly differentiated adenocarcinoma, consistent with metastasis (Fig. II). Soon after, a USG guided trucut biopsy was also done from the same site. Histopathology confirmed metastatic adenocarcinoma in triceps muscle (Fig. II inset).

CASE 2: Forty three year female presented with a nodule in left thyroid lobe. A diagnosis of poorly differentiated carcinoma was given on the FNA smears of thyroid. Detailed clinical history revealed that she was a known case of poorly differentiated squamous cell carcinoma, cervix. On review of slides focal areas showed squamoid differentiation (Fig. III).

\section{DISCUSSION:}

There is an increasing incidence of malignancy globally; cancer associated morbidity and mortality is major consequence of distant metastasis and advanced stage of disease ${ }^{4}$. It is estimated that metastasis is responsible for about $90 \%$ of cancer deaths. This is a significant reason why cancer management cannot deliver its maximum benefits ${ }^{1,3}$. It is necessary to understand the pathogenesis and patterns of metastatic spread. Metastasis is the general term used to describe the spread of cancer cells from the primary tumor to surrounding tissues and to distant organs. Cancers of esophagus and cervix are common and have predictable routes of spread like liver, lung, bones and lymph nodes. Rare sites of metastasis are now being described in the literature ${ }^{1,3,5}$.

Unusual organs where esophageal carcinoma metastatic deposits have been found are head \& neck, kidney, pancreas, spleen and very rarely to skin and skeletal muscles ${ }^{1,2,5}$. Physiologically, skeletal muscles are highly resistant to primary and metastatic cancers owing to high contractility, perfusion of blood and high mobility ${ }^{6}$. In the present case esophageal adenocarcinoma has spread to several skeletal muscles (left triceps brachii, right supraspinatous, posterior abdominal wall muscles and left medial thigh) throughout the body. The fine needle aspiration from triceps muscle showed malignant cells closely associated with skeletal muscle fibres. The core biopsy done from the same site at later date revealed the same findings in histopathology.

Unexpected metastasis from carcinoma cervix includes heart, brain, muscle ${ }^{3,7}$. Squamous cell carcinoma of cervix metastasing to thyroid gland is very $\operatorname{rare}^{8}$. Our case of carcinoma cervix showed metastatic deposits to thyroid. The cytology showed malignant squamoid cells admixed with thyroid follicular epithelial cells.

Probable route of spread in both cases is hematogenous. The cytopathological diagnosis in these cases helped the clinicians manage the further course of management accordingly.

\section{CONCLUSION:}

Some of the commonly prevalent malignancies may rarely metastasize to aberrant locations in the body. Thyroid is an uncommon site for metastatic squamous cell carcinoma and so is skeletal muscle for metastatic adenocarcinoma. These cases highlight the need for an awareness of the possibility of potential metastatic deposits in unexpected sites. As a cytopathologist, we must exercise clinical acumen with detailed clinical history before rushing to any diagnosis. Keeping the vision broad and awareness high can benefit the patient and the treating physician in getting quick and precise diagnosis for planning further course of treatment through a cost effective procedure of fine needle aspiration. 


\section{AUTHOR CONTRIBUTIONS:}

1. Srivastava Ruchi: Diagnosis, Preparing Manuscript

2. Tuli Preeti: Diagnosis, Proof reading

3. Das Poonam: Diagnosis, Proof reading

CONFLICT OF INTEREST: There is no conflict of interest in this study.

ETHICAL APPROVAL: Ethical approval was taken from the patients, who consented to publishing of their clinical details.

FUNDING INFORMATION: No funds were taken for the study.

\section{REFERENCES:}

1. Shaheen O, Ghibour A, and Alsaid B. Esophageal Cancer Metastases to Unexpected Sites: A Systematic Review. Hindawi Gastroenterology Research and Practice Volume 2017, Article ID 1657310, 13.

2. ChenY, Tang W, Xiao H, Chen J, ZhaoH, Shi J. An isolated unusual digit metastasis from esophageal carcinoma: a case report. OncoTargets and Therapy 2017:10 2449-2452.

3. Bhandari V, Kausar M, Naik A, Batra M. Unusual Metastasis from Carcinoma Cervix. The Journal of Obstetrics and Gynecology of India (September-October 2016) 66(5):358-362.

4. Seyfried TN, Huysentruyt LC. On the Origin of Cancer Metastasis. Crit Rev Oncog. 2013 ; 18(1-2): 43-73.

5. Mendiola VL, Willis M. Esophageal Adenocarcinoma with Extensive Metastasis to Unexpected Sites: A Case Report. Case Rep Oncol 2018; 11: 742-750.

6. Acinas Garcia O, Fernandez FA, Satue EG, et al. Metastasis of malignant neoplasms to skeletal muscle. Rev Esp Oncol. 1984; 31: 57-67.

7. Benoulaid M, Elkacemi H, Bourhafour I, Khalil J, Elmajjaoui S, Khannoussi B, Kebdani T and Benjaafar N. Skin metastases of cervical cancer: two case reports and review of the literature. Journal of Medical Case Reports, September 2016, Open Access.

8. CelikSU, BesliD, SakSD, GencV. Thyroid gland metastasis from Cancer of the uterine cervix: An extremely rare case report. ActaMedica. 2016; 59(3). 97-99.

\section{FIGURE LEGENDS:}

Fig. I

PET positive intramuscular deposits in left triceps brachii, right supraspinatous, posterior abdominal wall muscles and left medial thigh muscles in an elderly male, known case of carcinoma esophagus

Fig. II

Cytology of the aspirate from mass in left triceps muscle showing features of poorly differentiated adenocarcinoma. (May Grunwald, 100X). INSET: Histopathology confirms adenocarcinoma infiltrating skeletal muscle. (Hematoxylin and Eosin, 100X)

Fig. III

Cytology of the aspirate from thyroid nodule showing poorly differentiated squamous cell carcinoma in a forty three year female, known case of Squamous cell carcinoma cervix (May Grunwald, 100X) 


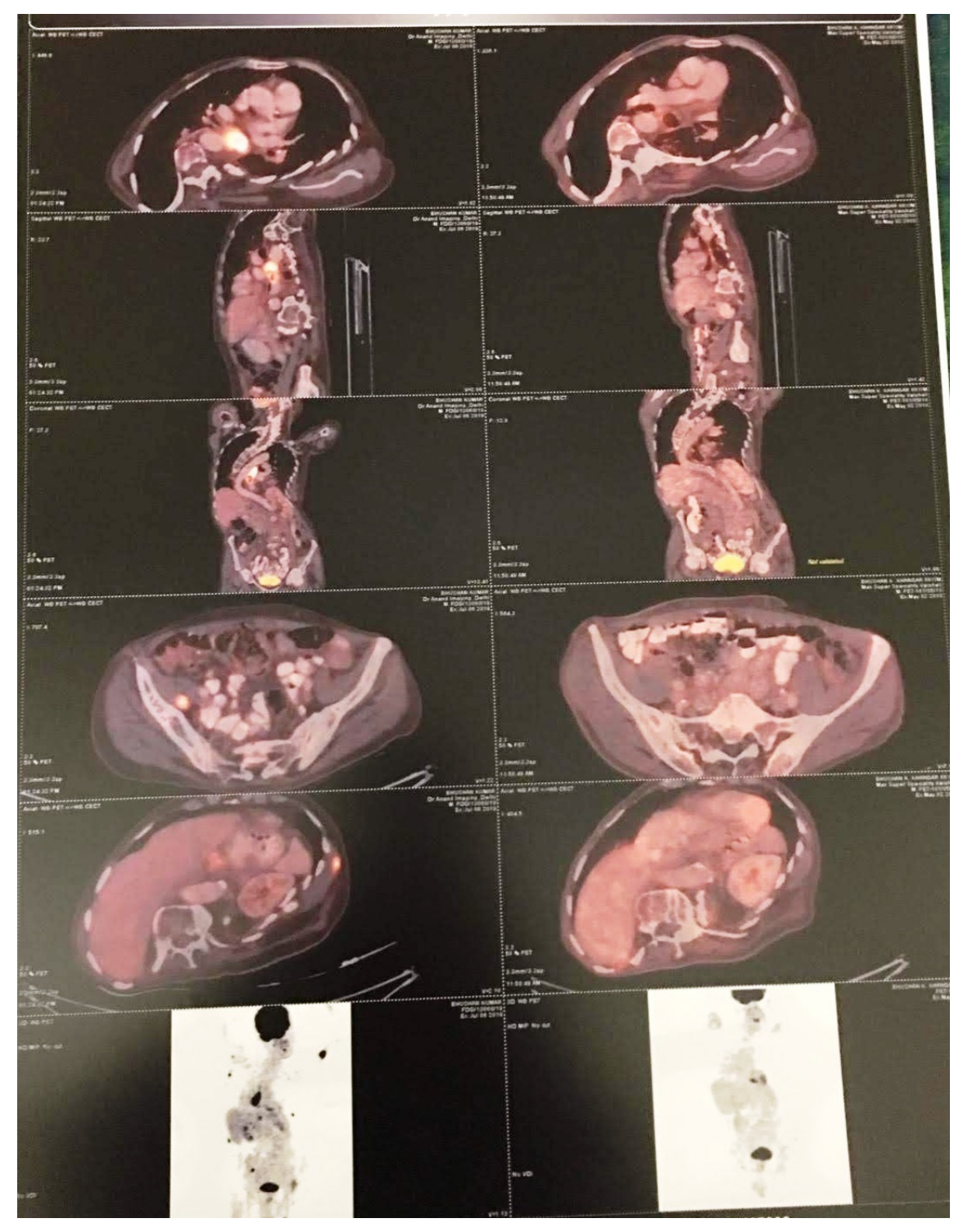



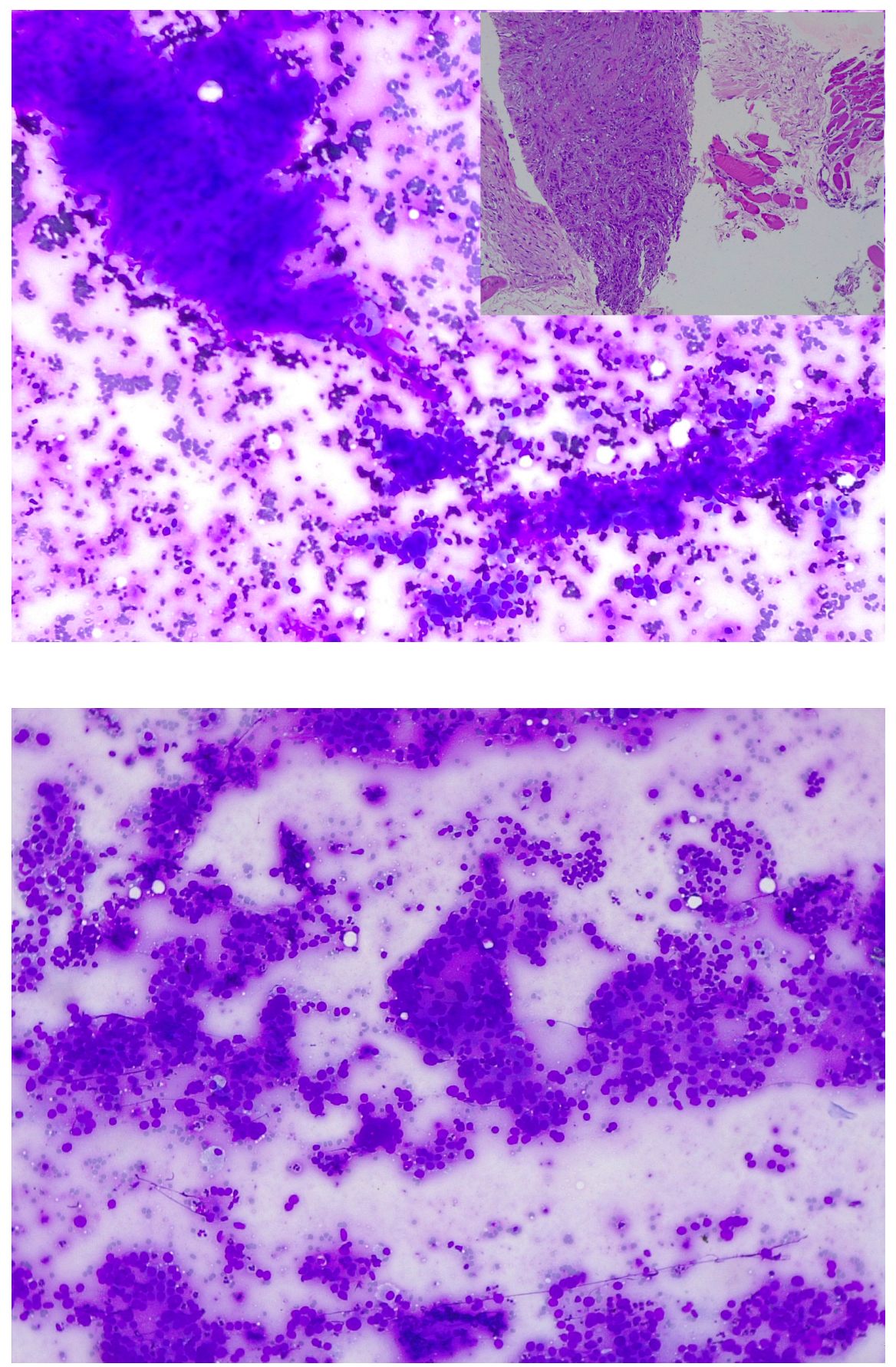